\title{
FORMULATION OF ECONOMICAL MICROBIAL FEED USING DEGRADED CHICKEN FEATHERS BY A NOVEL STREPTOMYCES SP: MITIGATION OF ENVIRONMENTAL POLLUTION
}

\author{
Jayapradha Ramakrishnan*; Hariram Balakrishnan; Selvaraj Thirupathi Kumara Raja; Natarajan \\ Sundararamakrishnan; Sadagoban Renganathan; Venkatesh Nagarajan Radha
}

Department of Biotechnology, School of Chemical and Biotechnology, SASTRA University, Thanjavur-613 401

Submitted: December 23, 2009; Returned to authors for corrections: November 12, 2010; Approved: March 14, 2011.

\begin{abstract}
A new Streptomyces sp. IF 5 was isolated from the feather dumped soil and found to have a tremendous keratinase activity. The strain enabled the degradation of the chicken feathers very effectively in $60 \mathrm{~h}$. The 16S rRNA sequence of 1474 bp long was submitted to the National centre for Biotechnological information. The keratinolytic activity in the culture medium was $1181 \mathrm{U} / \mathrm{ml}$. The release and analyses of sulphydryl groups in the culture medium evident the degradation activity by the Streptomyces sp. IF 5. The idea of the present study was to use the degraded chicken feathers as the substrate for the growth and cultivation of microorganisms. We have designed a very economical culture medium that includes the usage of some basal salts alone and degraded chicken feathers $(10 \mathrm{~g} / \mathrm{l})$. The results of the specific growth rate of the tested microbes confirm the usage of the new designed medium for microbial culturing.
\end{abstract}

Key words: keratinase activity, Streptomyces sp, microbial feed, chicken feather.

\section{INTRODUCTION}

Feathers are produced in large amounts as a by-product at poultry processing plants, reaching millions of tons annually. Removal of them is a major problem for processing plants and poultry farms (10). Feathers are formed from beta keratin which resists chemical agents and enzymatic lysis. The chemical activity of keratin is connected in a significant degree to the cystine content and the disulphide bond which is formed between two cysteine molecules is responsible for the high strength of keratin and its resistance against the action of proteolytic enzymes. $(16,21)$.

There are certain microorganisms that can synthesize keratinases. Keratinolytic microbes are widespread in nature, and largely isolated from poultry wastes that are mostly fungi, bacteria of the genera Bacillus and Streptomyces (19). The keratinases enzymes have gained biotechnological impetus only recently. Since feathers are almost pure keratin protein consisting of amino acids, feather wastes represent a potential alternative to expensive dietary ingredients for animal feedstuffs (6).

Currently, some industries are involved in feather meal

*Corresponding Author. Mailing address: Assistant professor, Microbiology division, School of Chemical \& Biotechnology, SASTRA University, Thanjavur - 613 401. Tamilnad.; Tel.: 914362 - 304193 Fax: 914362 - 264120.; E-mail: jayapradha @ scbt.sastra.edu 
production by steam pressure cooking, and many scientists have worked to find the nutritional value of the feather meal. Although the feather meal is an important source for animal production, it represents low digestibility (7). The natural existence of keratin-degrading microorganisms offers more nutritionally balanced and digestible product. The study on the protein and aminoacid composition of the microbially treated and untreated feathers showed higher amount of lysine, methionine and arginine in the fermented feather, due to the possibility of secreting limiting amino acids by the microbes, concluding the microbial biomass can also be a good rich protein source (17).

Their growing importance is mainly contributed to the isolation of keratinases from non-pathogenic microorganisms and their ability to degrade the tough insoluble keratin of feather and convert it into economically useful feather meal, nitrogenous fertilizers, biodegradable films, glues and foils (8). The production of aminoacids from the fermented feather is also a great demand in the industries. Keratinases are being used in many industrial sectors like detergent, medicine, cosmetics, leather, feed, particularly in the use of Bioresources international's Versazyme for feather meal production (8). Keratinases could also play other important role in, aerobic digestion of poultry waste to generate natural gas, in textile industries to improve shrink proofing wool and for cleaning obstructions in sewage system during wastewater treatment (22).

Hence the present study orients towards the innovative application of feather waste that is, the formulation of a new economical medium for the growth of microbes using the degraded feather. And it also includes, the isolation of efficient keratin degrader, followed by its taxonomical investigation, enzyme activity, SEM-EDAX analysis, and estimating the nutritive value of degraded feather medium.

\section{MATERIALS AND METHODS}

\section{Isolation of keratin degrader}

The feather dumped soil was collected from a local poultry farm at Thanjavur, Tamil Nadu, India. The soil samples were pre-treated for 30 minutes at $60^{\circ} \mathrm{C}$ to eliminate unwanted microorganisms and serially diluted in saline water up-to $10^{5}$. The Streptomyces sp was isolated using starch casein nitrate agar and incubated at $30^{\circ} \mathrm{C}$ for 14 days. The media was supplemented with carbendizim $400 \mathrm{mg} / \mathrm{l}$ after sterilization (11). The isolates were streaked on agar slants for further studies.

\section{Test for keratin degradation}

A loopful of 8 days old test isolates were inoculated in $100 \mathrm{ml}$ of sterilized basal salt medium (13) containing $0.5 \mathrm{gm}$ of fresh, cleaned and sterilized whole chicken feathers. All the flasks were kept in rotary shaker (SCIEGENEICS, Orbitek, India) at $110 \mathrm{rpm}$ for 28 days at $28^{\circ} \mathrm{C}$ in triplicates. The selection of isolate for taxonomical investigation and enzyme assay were based on rapid degradation of feathers.

\section{6s rRNA sequencing approach and Phylogenetic analysis}

The Genomic DNA of the test strain Streptomyces IF 5 was isolated using the procedure of Hopwood et al.,1985 (9). A PCR was performed in order to amplify the $16 \mathrm{~S}$ ribosomal DNA (rDNA) of the Streptomyces strain. The primers used were direct and reverse primers 5' AGAGTTTGATCCTGGCT CAG 3' and 5' GGTTACCTTGTTACGACTT 3. The PCR products were excised from an agarose gel electrophoresis, purified with a GENEI kit and sequenced using DNA sequencer (ABI 3100). Sequence similarity search was made for the 16S rRNA sequence of IF 5 using BLAST search (NCBI) and the ribosomal Database project. Evolutionary tree was inferred by using the neighbour joining method (18). The clustal X program (25) was used for multiple alignment and phylogenetic analysis.

\section{Inoculum preparation}

Spore suspension of Streptomyces sp. IF5 was prepared by inoculating a loopful in the seed medium containing Starch $1 \%$ (w/v), Glucose $0.5 \%(w / v)$, Yeast extract $0.2 \%(w / v), \mathrm{K}_{2} \mathrm{HPO}_{4}$ 
$0.1 \%(\mathrm{w} / \mathrm{v}), \quad \mathrm{MgSO}_{4} \cdot 7 \mathrm{H}_{2} \mathrm{O} \quad 0.05 \% \quad(\mathrm{w} / \mathrm{v})$. The flask was incubated at $28^{\circ} \mathrm{C}$ for $24 \mathrm{~h}$ on rotary shaker at $110 \mathrm{rpm} .25 \mathrm{ml}$ of the seed culture was inoculated into one liter of basal salt medium containing $5 \mathrm{~g}$ of fresh, cleaned sterilized feathers, and kept at $110 \mathrm{rpm}$ for 3 days. The changes in $\mathrm{pH}$ of the medium were also monitored at the regular intervals of $12 \mathrm{~h}$.

\section{Enzyme activity assay}

Keratinase activity was determined spectrophotometrically by the method of Mona, 2007 (16). The reaction mixture consisted of $1 \mathrm{ml}$ diluted enzyme solution and $0.1 \mathrm{~g}$ feather keratin (HiMedia, India) in $5 \mathrm{ml}$ borate buffer ( 50 $\mathrm{mM}, \mathrm{pH} 9$ ) and incubated for 4 hours at $40^{\circ} \mathrm{C}$. The reaction was stopped with $1 \mathrm{ml}$ of $10 \%$ trichloroacetic acid (TCA) for 30 minutes at room temperature. The mixture was centrifuged and the released amino acids were measured as tyrosine by Lowry's method (15). The tests were also performed using casein as substrate.

\section{Thiol assay}

The disulphide released in the degradation medium was assayed by the method of Ellman, 1959. The assay was performed at regular intervals of $12 \mathrm{~h}$ for 3 days.

\section{Scanning electron microscope and Energy Dispersive spectroscopy (EDAX) analysis}

The degradation of the feathers was characterized by SEM. The culture broth containing degraded feathers were filtered, washed twice by distilled water and the substrates were dried. The degraded feather (DF) and the non-degraded feather (NDF) were pasted separately in a stub using double sided adhesive carbon conducting tape and gold sputtered. The sample was analyzed in the scanning electron microscope (Hitachi S-3000 H) using photomultiplier detector and images were taken at $50 \mathrm{X}$ and $250 \mathrm{X}$. The elemental composition of both DF and NDF were determined by EDAX (made by Thermo Electron Corporation) using silicon drift lithium detector.

\section{Formulation of Degraded feather medium (DFM)}

The feathers degraded by the strain IF 5 were collected from the culture broth and purified by washing with double distilled water, followed by drying. The feathers were dried using the spray drier to yield powered feather meal. The meal obtained was used in the formulation of DFM of composition: sodium chloride 5.0; potassium dihydrogen phosphate 1.5; degraded feather 10; agar 15 (g/l). The isolates, E.coli, B.subtilis, B.polymyxa, B.licheniformis, S.aureus, Pseudomonas aueroginosa, Proteus vulgaris, Aspergillus flavus, Streptomyces sp. were grown and their growth was evaluated in three different media namely, Buffered peptone water agar (BPWA), Buffered water agar (BWA), DFM and Feather medium containing raw feathers.

The growth of the microbes on the newly formulated DFM was tested by using the $10^{6}$ dilution by spread plate technique. For the purpose of comparison during microbial cultivations, BPWA and BWA were used concurrently as reference medium. All the media were sterilized by autoclaving at $121^{\circ} \mathrm{C}$ at $15 \mathrm{lbs}$ for 15 minutes.

\section{RESULTS AND DISCUSSION}

\section{Phylogenetic analysis of strain IF 5}

Among the isolates from the feather dumped soil collected in the local poultry farm, Streptomyces sp. IF5 was capable degrading the chicken feathers in $60 \mathrm{~h}$. It is evident from this study that the isolated strain could grow on the minimal medium containing the keratin as the substrate for carbon and nitrogen source. The strain IF5 exhibiting the highest feather degradation was chosen for taxonomical investigation. The phylogenetic analysis of the strain IF5 based on the 16s rRNA showed that the sequence is $1474 \mathrm{bp}$ long, and has a highest homology (96\%) with Streptomyces A515 Ydz-FQ. The Phylogenetic analysis (Fig. 1), at the RDP, placed the strain 
within the evolutionary radiation encompassed by the genus Streptomyces, where the $16 \mathrm{~S}$ rRNA gene sequence of Streptomyces brasiliensis St. NBRC 12596 was identified with the highest probability (0.97) as the closest matching sequence to IF 5. The homology data differs by $4 \%$ suggesting that the strain IF 5 might be a new species and thus it was designated as Streptomyces sp. IF5.

The nucleotide sequence of this novel bacterium has been deposited in the National Centre For Biotechnological Information and obtained GENBANK accession number FJ951435. Similarly, Tatineni et al., 2008 (24) proposed their isolate Streptomyces sp could be a novel species showing nearest homology of $97 \%$.

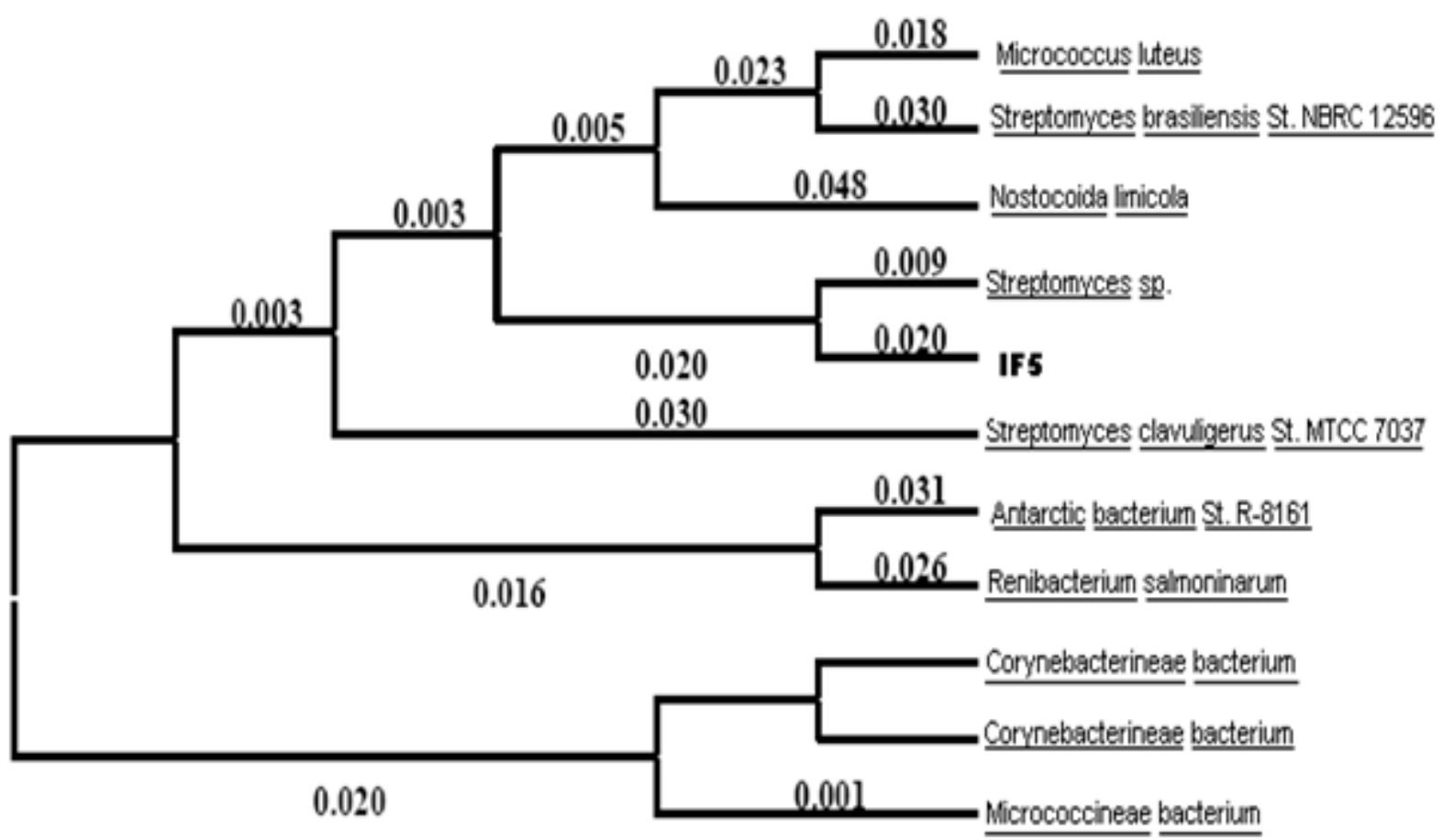

Figure 1. Neighbor-joining tree based on 16s rDNA gene sequences showing Relationship between the strain IF 5 and other Streptomyces sp.

\section{Enzyme assay}

Data obtained for the time course experiment was conducted over a period of $120 \mathrm{~h}$. The enzyme production commenced on $12^{\text {th }} \mathrm{h}$ and reached a peak at $60 \mathrm{~h}$. The alkalinity $\mathrm{pH}$ (8.5) of the culture medium during the course time of degradation indicates the keratinolysis, since the drift in $\mathrm{pH}$ is considered as one of the significant parameter (13). The enzymatic activity was $1181 \mathrm{U} / \mathrm{ml}$. The maximum degradation was shown by Tatineni et al., 2008 (24) in 96 h. And a thorough review of the literature survey on microbial keratinolysis enzymatic activity shows that strain IF 5 shows the maximum keartinase activity at $60 \mathrm{~h}$ itself. $(12,20)$

\section{Sulfhydryl analysis}

During the enzymatic hydrolysis of feather keratin, the release of sulfhydryl groups in the medium was monitored at the regular intervals of $12 \mathrm{~h}$ for 3 days (Fig. 2). The increase in the sulfhydryl groups reached the peak in 2.5 days, without the addition of any disulphide containing substrates. Bockle and Muller, 1997 (2) studied the formation of thiol groups after the 
addition of cystine in feather medium. The denaturation of keratin is accomplished with the enzyme reductase present on the mycelial surfaces, which help in the breaking of disulphide bonds. The effective degradation of chicken feathers by the strain IF 5 is also evident from the Scanning electron micrograph (Fig. 3).

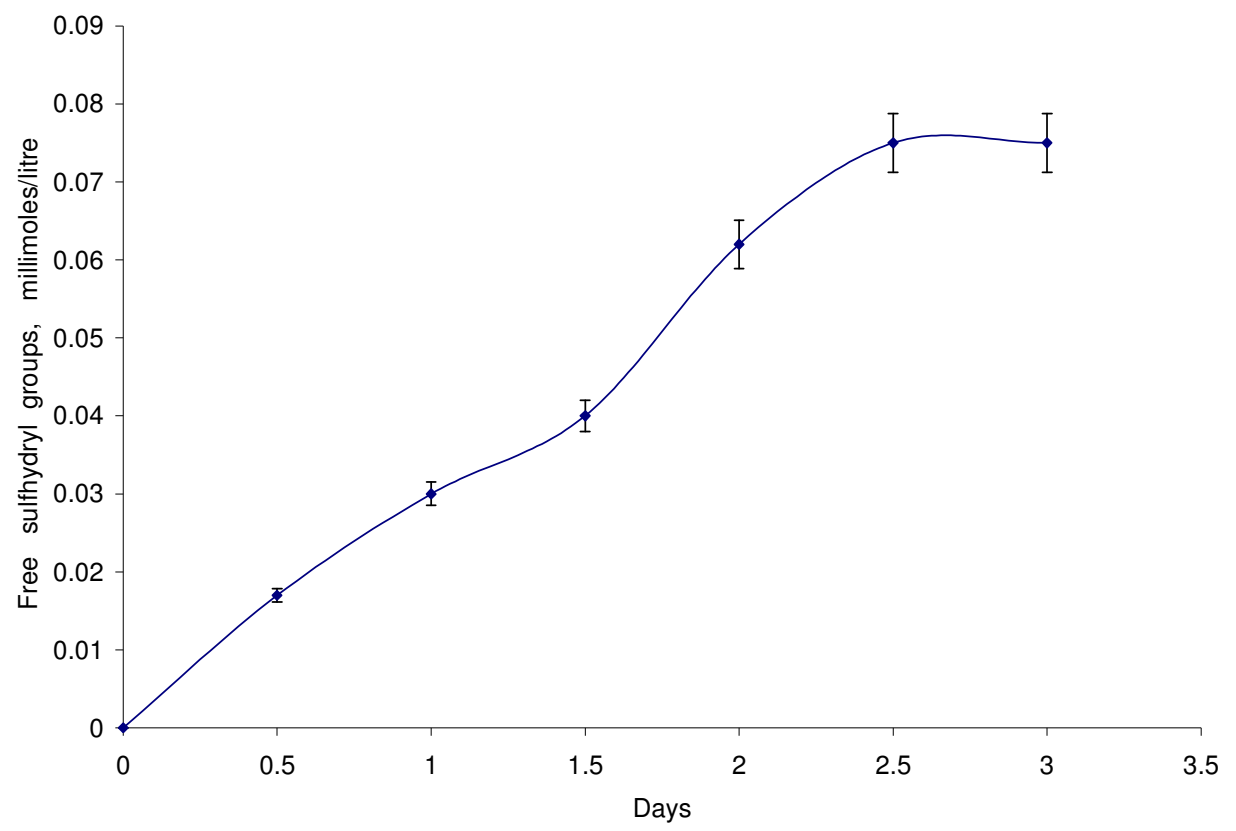

Figure 2. Estimation of released sulfhydryl groups in the culture medium. Error bar shows $\pm 5 \%$ error.
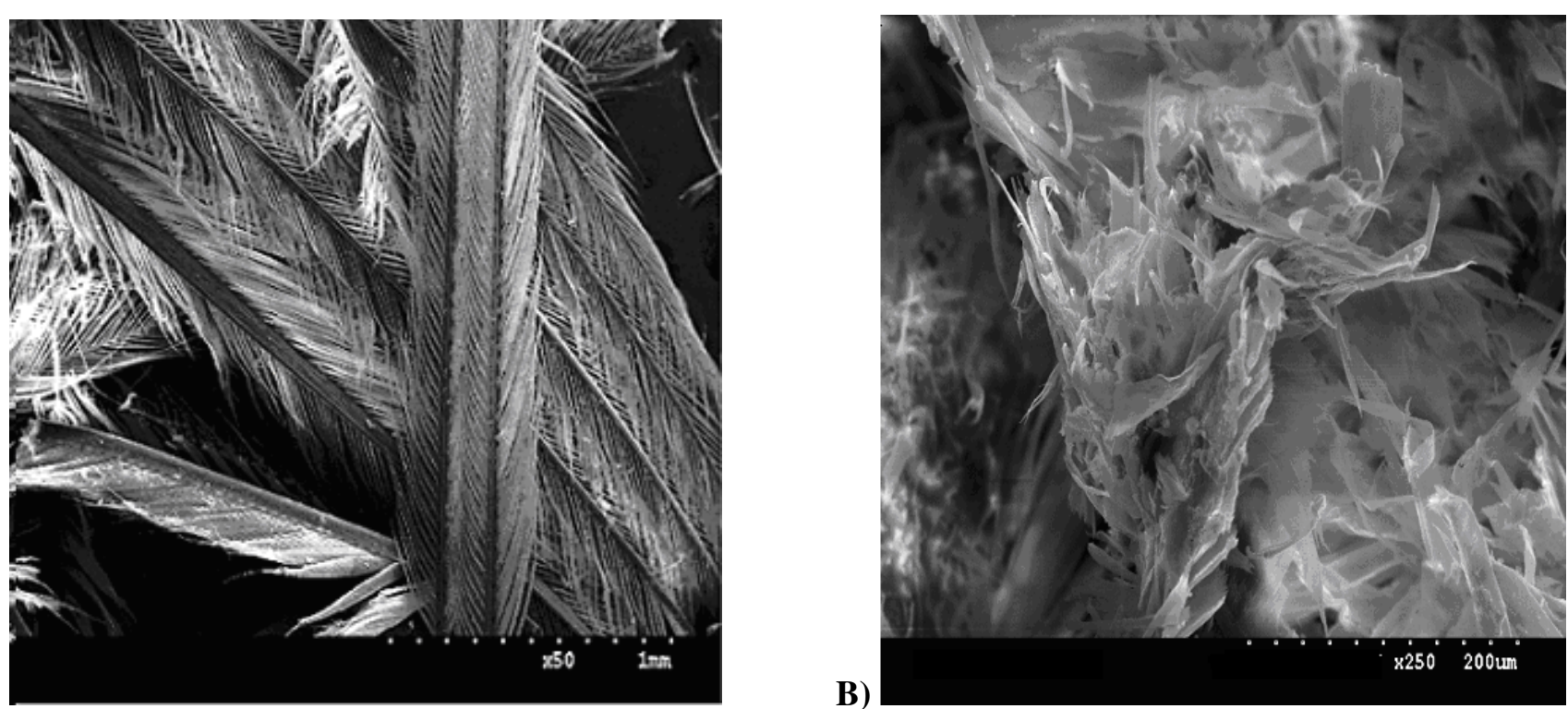

Figure 3. Scanning electron micrographs of control (a) and degraded feathers (b) by the strain IF 5. 


\section{Evaluation of microbial growth}

Bulk discarding of chicken feathers is an environment threat though many methods like land filling, production of natural gas, fertilizer, and feather meal were adopted $(1,17)$.

Thus, the main objective of the study was to formulate the microbial medium from degraded feather waste in comparison with a commercial media like peptone agar. When microbial growth was examined in the agar plates, the DF medium containing sodium chloride 5.0; potassium dihydrogen phosphate 1.5, degraded feather 10; agar $1.5(\mathrm{~g} / \mathrm{l})$, produced comparable colony counts with the reference medium (BPWA). Fig. 4 clearly pictures the newly formulated DFM were observed to support the growth against the tested microbes. Growth rate for DFM was moreover very similar to BPWA, and the growth rate can be much more increased in DFM by increasing the substrate concentration. The feather medium which has raw or nondegraded feathers, doesn't support the growth of any of the microbes used. These results supports that the newly formulated economic media could support the tested microorganisms. The microbial growth in the DFM can be increased than the reference media used by increasing the percentage of substrate concentration in medium. Similarly Poopathi and Abitha, 2008 (18) used the biodegraded poultry waste for the production of mosquitocidal toxins. Previous literatures have documented the keratinase producing strains from Streptomyces sp $(3,23,26)$ their production, optimization parameters, and applications in various fields as biofertilizer, as glues etc. However the usage of degraded feather as the economical medium for the cultivation of microbes has not been reported.

Feather meal protein is classified as insoluble keratin. The total cysteine content of feather meal and the rate of its liberation by pancreatic digestion may also serve as the indication of the nutritive value for the poultry. Recently, Keratin agar plates and feather meal agar plates were used by many researches for the isolation and screening of keratin degrader. The keratin agar medium consists of ball milled chicken feathers, which can be used as substrate only by those organisms possessing the keratinase enzyme $(5,14,19)$. Here we designed the economic medium using the digested feathers for the cultivation of microbes.

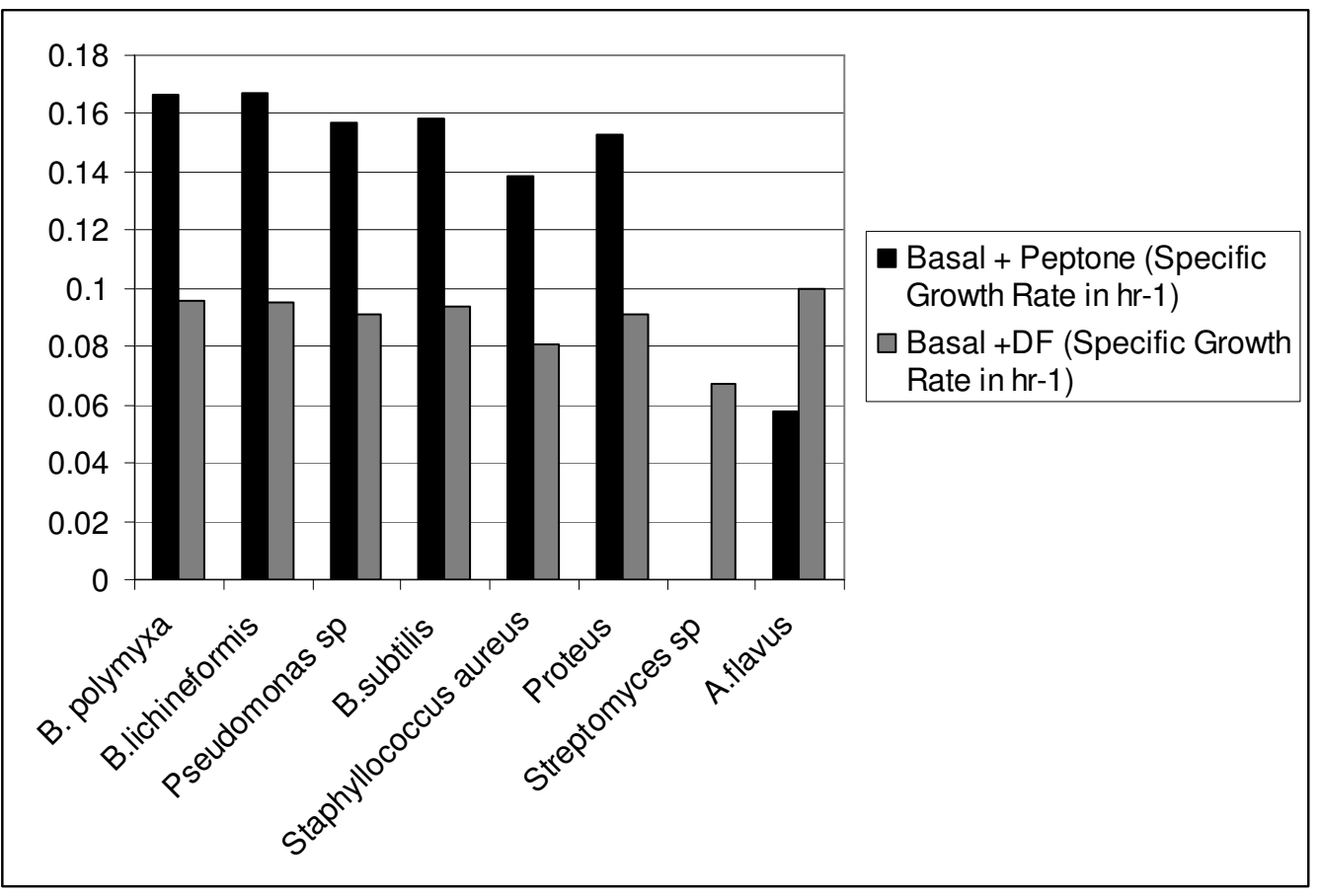

Figure.4. Evaluation of microbial growth in DFM. 


\section{Cost- effective analysis}

Cost-effective analysis from Table 1 shows that DFM medium consists of disposable waste like degraded feather which is free of cost, being a poultry waste and trace elements which are cheap and readily available. On the contrary, preparation of $1 \mathrm{~L}$ of BPW involves a cost of US \$2. Thus, the use of feather waste as bacterial culture medium is highly economical.

Table 1. Comparative costing for BPW and DFM

\begin{tabular}{llll}
\hline Culture medium & Main constituents of the medium & Quantity required g/l & Total cost (US \$) \\
\hline $\begin{array}{l}\text { BPW } \\
\text { (Himedia, India) }\end{array}$ & Commercially available media & 20 & 2 \\
DFM & $\begin{array}{l}\text { Nacl+ potassium dihydrogen } \\
\text { phosphate+ degraded feather+ agar }\end{array}$ & $5+1.5+10$ & 5 cents \\
\hline
\end{tabular}

\section{Nutritive value of DFM}

Disulphide and hydrogen bonds makes keratin a stable protein and not easily utilizable by many microbial groups except by the keratin degrading species. The attempt was being made to use the degraded feather as microbial feed. But during the biotreatment of feathers, some nutrients may be lost in the cultivation medium was the basic assumption. Hence the EDAX analysis was made to compare the nutritive value of feathers being degraded and the non degraded feather. The
EDAX analysis of DF does not show much decrease in the elemental composition when compared to NDF. From Fig 5.a and 5.b, it can be clearly confirmed the nutritive value of the chicken feathers were not lost even after keratinolytic degradation. Based on the experimental observations, the microbially treated feathers were containing essential nutrients for the growth of other microorganisms. Based upon these results, this was the first attempt in utilizing these sources as growth medium for bacteria, fungi and Streptomyces.

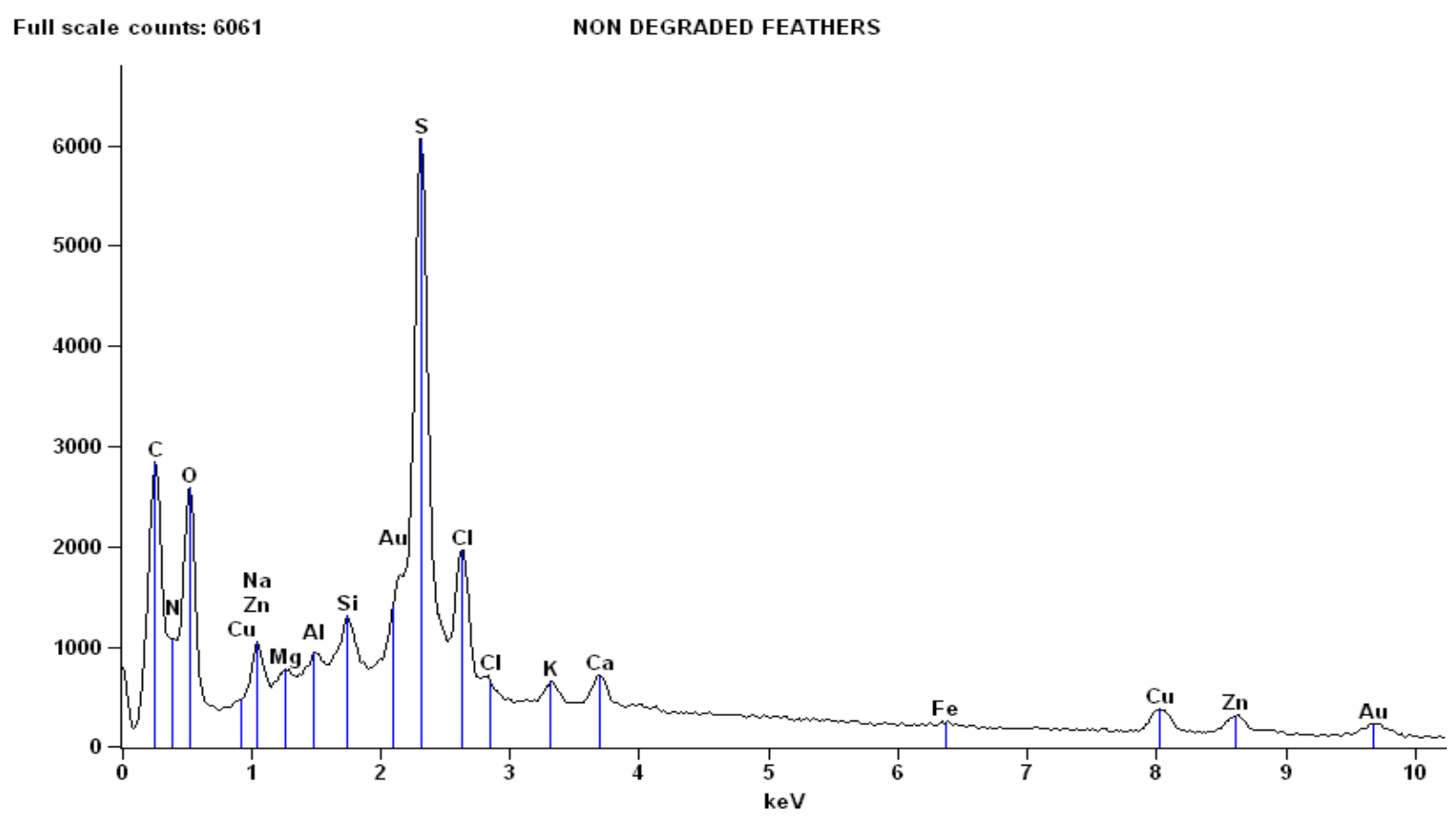




\begin{tabular}{cclcc}
\hline Element & Net counts & ZAF & Weight \% & Atom \% \\
\hline$C$ & 31896 & 2.767 & 41.89 & 49.46 \\
$N$ & 8563 & 9.327 & 24.51 & 24.82 \\
$O$ & 10.510 & 25.98 & 23.03 \\
$\mathrm{Na}$ & 25859 & 3.774 & 0.70 & 0.43 \\
$\mathrm{Mg}$ & 4710 & 2.518 & 0.06 & 0.03 \\
$\mathrm{Al}$ & 915 & 1.915 & 0.07 & 0.04 \\
$\mathrm{Si}$ & 1481 & 1.507 & 0.22 & 0.11 \\
$\mathrm{~S}$ & 5568 & 1.253 & 2.95 & 1.30 \\
$\mathrm{Cl}$ & 69826 & 1.285 & 0.74 & 0.30 \\
$\mathrm{~K}$ & 16641 & 1.199 & 0.12 & 0.04 \\
$\mathrm{Ca}$ & 2710 & 1.151 & 0.20 & 0.07 \\
$\mathrm{Fe}$ & 4196 & 1.224 & 0.04 & 0.01 \\
$\mathrm{Cu}$ & 463 & 1.275 & 0.58 & 0.13 \\
$\mathrm{Zn}$ & 4558 & 1.273 & 0.52 & 0.11 \\
$\mathrm{Au}$ & 3266 & 1.616 & 1.42 & 0.10 \\
\hline Total & 3874 & & 100.00 & 100.00 \\
\hline
\end{tabular}

Figure 5a. Chemical composition of non degraded feathers obtained from EDAX

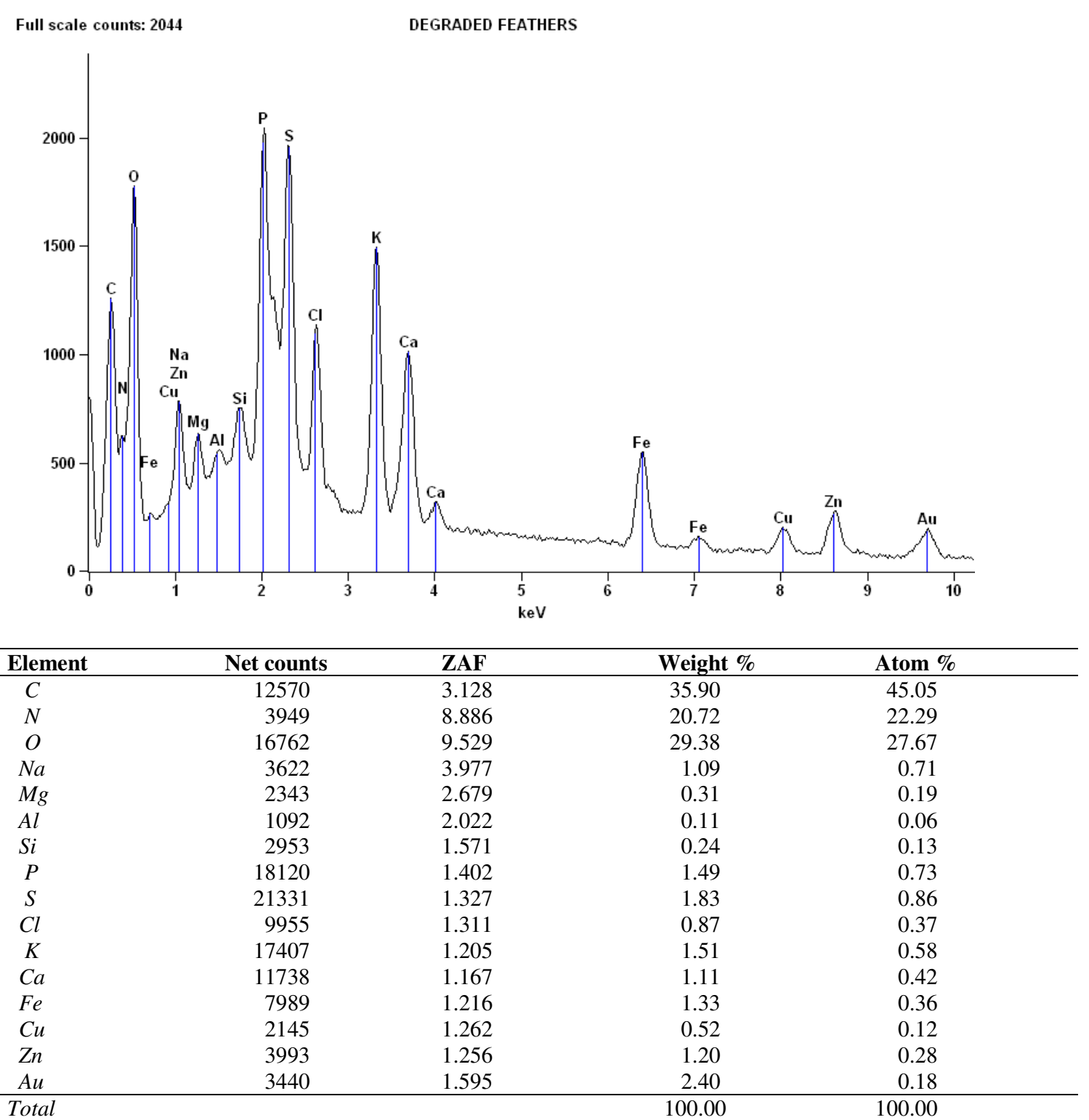

Figure 5b. Chemical composition of degraded feathers obtained from EDAX 


\section{CONCLUSION}

The study clearly showcases an innovative idea as well as a new approach for the utilization of degraded feather in the formulation of economical microbial feed; thereby providing the key to recycle huge amounts of nutritious feathers discarded by the poultry industries.

\section{ACKNOWLEDGEMENTS}

We thank Prof. R. Sethuraman, Vice-Chancellor of SASTRA University for providing fund under the innovative proposal scheme to carry out this research successfully.

\section{REFERENCES}

1. Bertsch, A.; Coello, N. (2005). A biotechnological process for treatment and recycling poultry feathers as a feed ingredient. Bioresour. Technol. 96 (15), 1703-1708.

2. Bockle, B.; Muller, R. (1997). Reduction of disulfide bonds by Streptomyces pactum during growth on chickens. Appl. Environ. Microbiol. 63 (2), 790- 792.

3. Dastager, G.S.; Lee, J.C.; Li, W.J.; Kim, C.J.; Agasar, D. (2009). Production, characterization and application of keratinase from Streptomyces gulbargensis. Bioresour. Technol. 100 (5), 1868-1871.

4. Ellman, G.L. (1959). Tissue sulfhydryl groups. Arch. Biochem. Biophys. $82,70-77$.

5. Friedrich, J.; Gradisar, H.; Mandin, D.; Chaumont, J.P. (1998). Screening fungi for synthesis of keratinolytic enzymes. Lett Appl Microbiol. 28, $127-130$.

6. Gessesse, A.; Hatti-Kaul, R.; Gashe, B.A.; Mattiasson, B. (2003). Novel alkaline proteases from alkaliphilic bacteria grown on chicken feather. Enzym Microb Tech. 32 (5), 519-524.

7. Grazziotin, A.; Pimentel, F.A.; De Jong, E.V.; Brandelli, A.; (2006) Nutritional improvement of feather protein by treatment with microbial keratinase Animal Feed. Science and Technology. 126 (1), 135-144.

8. Gupta, R.; Ramnani, P. (2006). Microbial keratinases and their prospective applications:an overview. Appl Microbiol Biotechnol. 70 (1), 21-33.

9. Hopwood, D.A.; Bibb, M.J.; Chater, K.F.; Kieser, T.; Bruton, C.J; Kieser, H.M.; Lydiate, D.J.U.; Smith C.P.; Ward J.M.; Schrempf, H. (1985). Genetic manipulation of Streptomycin- A laboratory manual (Norwich: The John Innes Foundation)
10. Jann, M.I.; Krizova , L.; LeFevre, C.A.; Keener, H.M.; Elwell ,D.L.; Edward, H.; Burtt, J.R. (2001). Bacterial inoculum enhances keratin degradation and biofilm formation in poultry compost. J Microbiol Meth. 47(2), 199-208.

11. Jayapradha, R.; Murugesh, S.; Mahesh, N. (2009). Streptomyces sp. SCBT from rhizosphere soil of medicinal plants exhibiting antagonistic activity against human pathogens. Iranian journal of Biotechnology. 7 (2), 75-82.

12. Kansoh, AL.; Hossiny, EN.; Hameed, E.K.A. (2009). Keratinase Production From Feathers Wastes Using Some Local Streptomyces Isolates. Aust. J. Basic appl. sci. 3(2), 561-571.

13. Lal, S.; Rajak, R.C.; Suresh, K, Hasija. (1999). In vitro degradation of keratin by two species of Bacillus. J. Gen. Appl. Microbiol. 45 (6), 283287.

14. Letourneau, F.; Soussotte, V.; Bressollier, P.; Branland, P.; Verneuil, B. (1998). Keratinolytic activity of Streptomyces sp. S.K1-02: a new isolated strain. Lett Appl Microbiol. 26 (1), 77-80.

15. Lowry, O.H.; Rosebrough, N.J.; Farr, A.L.; Ranall, R.T. (1951). Protein measurement with 338 the folin phenol reagent. J. Biol. Chem. 193, 265273.

16. Mona, A.E. (2007). Isolation and Partial Characterization of Extracellular Keratinase from a Novel Mesophilic Streptomyces albus AZA. Res J Agr Biol Sci. 3(6), 808-817.

17. Onifade, A.A.; A1-Sane, N.A.; AI-Musallam, A.A.; Al-Zarban, S. (1998). Potentials for biotechnological applications of keratin-degrading microorganisms and their enzymes for nutritional improvement of feathers and other keratins as livestock feed resources. Bioresource Technology. 66, 1-11

18. Poopathi, S.; Abidha, S. (2008). Biodegradation of poultry waste for the production of mosquitocidal toxins. International Biodeterioration \& Biodegradation. 62 (4), 479-482.

19. Saito, N.; Nei, M. (1987). The neighbour-joining method: a new method for reconstructing phylogenetic trees. Mol Biol Envirol. 4 (4), 406- 425.

20. Sarita, A.; Neeraj, W. (2010). Degradation of Chicken Feather a Poultry Waste Product by Keratinolytic Bacteria Isolated from Dumping Site at Ghazipur Poultry Processing Plant. Int. J. Poult. Sci.. 9 (5), 482-489.

21. Savitha, G.J.; Tejashwini, M.M.; Revati, N.; Sridevi, R.; Roma, D. (2007). Isolation, Identification and Characterization of a Feather Degrading Bacterium. Int. J. Poult. Sci. 6 (9), 689-693. 19

22. Swetlana, N.; Jain, P.C. (2010). Feather degradation by strains of Bacillus isolated from decomposing feathers. Braz. J. Microbiol. 41(1)

23. Takahashi, K.; Yamamoto, H.; Yokote, Y.; Hattori, M. (2004). Thermal behavior of fowl feather keratin. Biosci. Biotechnol. Biochem. 68 (9), 875-881.

24. Tatineni, R.; Doddapaneni, K.; Chandra Potumarthi, R.; Nagaraj Vellanki, R.; Thomas Kandathil, M.; Kolli, N.; Mangamoori, L. (2008). Purification and characterization of an alkaline keratinase from 
Streptomyces sp. Bioresour. Technol. 99 (6), 1596-1602.

25. Thompson, J.D.; Gibson, T.J.; Plewniak, F.; Jaenmougin, F.; Higgins, D.G. (1997). The clustal X windows interface: flexible strategies for multiple sequence alignment aided by quality analysis tools. Nucleic
Acids Res. 25 (24), 4876-4882.

26. Ya-peng, C.; Fu-hong, X.; Jing,Y.; Jing-hua, L.U.; Shi-jun, Q. (2007). Screening for a new Streptomyces strain capable of efficient keratin degradation. J Environ Sci. 19 (9), 1125-1128. 